\title{
Flutter and Buffeting Control of Long-span Suspension Bridge by Pas- sive Flaps: Experiment and Numerical Simulation
}

\author{
Duc-Huynh Phan* \\ Department of Civil Engineering and Applied Mechanics, University of Education and Technology, Hochiminh city, Vietnam
}

\section{Ngoc-Trung Nguyen**}

Department of Mechanical \& Biomedical Engineering, Kangwon National University, Chuncheon-si, Gangwon-do, South Korea

\begin{abstract}
Flutter stability and buffeting response have been the topics of most concern in the design state of long-span suspension bridges. Among approaches towards the aerodynamic stability, the aerodynamic-based control method which uses control surfaces to generate forces counteracting the unstable excitations has shown to be promising. This study focused on the mechanically controlled system using flaps; two flaps were attached on both sides of a bridge deck and were driven by the motions of the bridge deck. When the flaps moved, the overall cross section of the bridge deck containing these flaps was continuously changing. As a consequence, the aerodynamic forces also changed. The efficiency of the control was studied through the numerical simulation and experimental investigations. The values of quasi-steady forces, together with the experimental aerodynamic force coefficients, were proposed in the simulation. The results showed that the passive flap control can, with appropriate motion of the flaps, solve the aerodynamic instability. The efficiency of the flap control on the full span of a simple suspension bridge was also carried out. The mode-by-mode technique was applied for the investigation. The results revealed that the efficiency of the flap control relates to the mode number, the installed location of the flap, and the flap length.
\end{abstract}

Key words: flutter, buffeting, passive control, flap, quasi-steady force

\section{Introduction}

Flutter has been realized to be one of the most dangerous aeroelastics of structures in civil engineering, especially after the disaster of the Tacoma Narrow Bridge. Flutter relates to both wind loads and structural response, from the perspective of control structure interactions. The flutter vibration mode is caused by self-excitation force from wind loads. When flutter occurs, the oscillatory motions regarding all degrees of freedom in the structure couple to create a single frequency called the flutter frequency. Also, the displacement is infinite by linear theory. Flutter could occur in both smooth and turbulent flows. The response of the bridge in turbulent flow in a wide range of wind speeds is called buffeting response.
This response is normally used to determine the size of the structural members and requires careful evaluation at the design stage.

The question regarding the effective flutter and buffeting control is of growing interest as the span length of suspension bridges increases. This has resulted in a variety of techniques to reduce or suppress the aeroelastic response. The most common control methods can roughly be divided into the structure-based method and the aerodynamics-based method. The former approach exploits stiffened girders and/ or eccentric mass to control the flutter phenomenon passively whereas the latter approach focuses on generating stabilizing aerodynamic forces from the flow to solve the flutter problem.

A high torsion rigidity truss-stiffening girder was widely
This is an Open Access article distributed under the terms of the Creative Commons Attribution Non-Commercial License (http://creativecommons.org/licenses/by$\mathrm{nc} / 3.0 /$ which permits unrestricted non-commercial use, distribution, and reproduction in any medium, provided the original work is properly cited. (c) * Lecturer, Ph.D., Corresponding author : huynhpd@hcmute.edu.vn

** Research professor, Ph.D., Email: ntnguyen@kangwon.ac.kr 
used in the design of a suspension bridge. For instance, the Akashi Kaikyo Bridge has a vertical stabilizer in the center span located along the centerline of the truss-type stiffening girder to improve aerodynamic stability. However, truss sections usually exhibit reasonably high wind forces (drag loading) which must be resisted by the bridge structure leading to the increase in the construction cost. The development of box-girders with a nearly streamlined section could also achieve the wind stability of a long span bridge. A twin-deck configuration with a center gap has been proven to be an effective means of improving the flutter characteristics (Fok et al., 2004a, 2004b; Kwok et al., 2012). However, the adequate stability cannot be assured beyond a certain limit in regard to length of spans (Brancaleoni, 1992; Ostenfeld and Larsen, 1992).

Research on aerodynamic control by using winglets and flaps (or being called control surfaces) was proposed and developed (Kobayashi et al., 1992, 1996, 1998, 2001 and 2005). The study was continued with experiments on passive flap control in turbulent and smooth flow (Phan and Kobayashi, 2011). However, the numerical simulation was not presented. Furthermore, the effects of flap control on the full span of the suspension bridge were not carried out. An extensive theoretical study on the active control of bridge flutter using a model similar to that proposed by Kobayashi was presented (Wilde et al., 1998; Preidikman and Mook, 1998; Nissen et al., 2004). The active model was then translated to a passive one (Wilde et al., 1999). Omenzetter et al. $(2000,2002)$ also proposed the passive flap control with springs and supplementary cables.

In order to study the effects of wind on structures, the time domain analysis may be the most effective approach. This approach can be done if forces acting on structures are expressed in the time domain. The famous self-excited forces suggested by Scanlan and Tomko (1971) contain frequencydependent coefficients. These forces are functions of flutter derivatives and reduced frequency. These flutter derivatives are found by experimental testing. To use these forces in the time domain, they have to be transformed into time dependency forces. This can be achieved by using indicial functions (Costa and Borri, 2006; Scanlan et al., 1974) or rational functions (Chen et al., 2000; Chen and Kareem, 2001; Cao and Sarkar, 2012). The simpler approach is to use quasi-steady theory. It is valid in both the time and frequency domain. These forces are the functions of the aerodynamic force coefficients: lift, drag, and moment coefficients.

In this study, the efficiency of mechanically driven flaps for controlling the aerodynamic stability of a bridge deck was investigated with both numerical simulation and experiment approaches whereby, a flap was mechanically controlled by the pitching motion of the deck and the aerodynamic damping or suppressing aerodynamic force was then produced. As shown in Figure 1, the flaps were installed on both sides of the bridge deck and allowed the pitching motion. Providing the appropriate pitching motion of the flaps, the aerodynamic suppressing forces produced by them overcome the aerodynamic excitation, thus the flutter and buffeting were suppressed. Sectional model tests were also conducted to investigate the effect of the mechanically driving flap on the aerodynamic control. To explore the effects of flap control on both two-dimensional and three-dimensional cases, the quasi-steady theory has been selected with the related force coefficients obtained from the experiment in the wind tunnel. In addition, the numerical study on flutter and buffeting passive control for a super-long span suspension bridge (3,000 m central span) has been taken for the analysis. A three-dimensional model in conjunction with mode-by-mode analysis has been considered in an attempt to predict the flutter speed and buffeting response for full span with and without flaps. The method of analysis in essence is based on the quasisteady forces method as used in the two-dimensional analysis.

\section{Two-dimensional analysis by quasi-steady forces}

The bridge deck section in this paper was a shallow box girder and was aerodynamically treated as a flat plate. The controlling flaps at both edges of the bridge deck were also assumed to be flat plates. Thus, the numerical model of the bridge deck with the controlling flaps is described as shown in Figure 1.

\subsection{Control method}

Figure 2 presents the bridge deck system having flaps which were mechanically driven by the rotational motion of

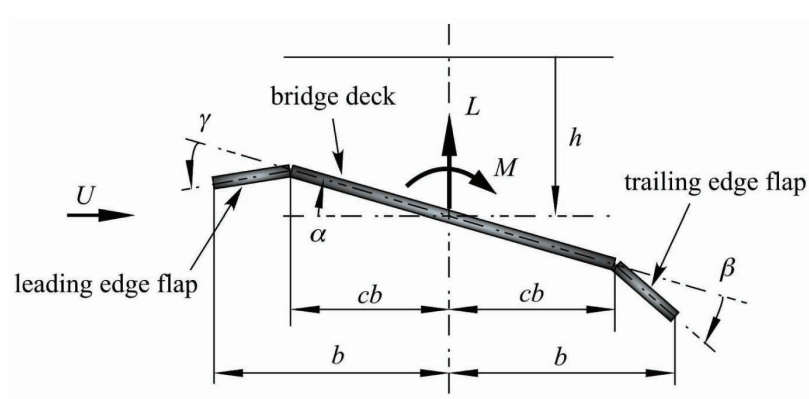

Fig. 1. A bridge deck with flaps installed at leading and trailing edges 
the deck. The flap was fixed with a hinge at the longitudinal edge of the bridge deck. Two hanger cables from a main cable were fixed to an anchor beam at its ends. A cross beam of the deck system was fixed to the anchor beam with a hinge. The gears $G_{s}$ and $G_{f}$ were fastened to the anchor beam and flap, respectively. Both gears were connected by a driving belt. When a bridge deck caused a torsion motion in its natural oscillation mode, hanger ropes nearly kept their vertical figure. The relative rotation angle was transmitted to the rotation of the flap through the driving belt with a given amplifying factor $G=R_{s} / R_{f}$ where $G_{s}$ and $G_{f}$ are the radiuses of the gear $G_{s}$ and $G_{f}$ respectively. Thus, the flap was driven just following the pitching motion of the bridge deck mechanically.

The same mechanism of the flap driving system was installed at the leeward side of the bridge deck. When the flaps were driven by the above mentioned manner, if we set the head-up motion of the bridge deck as $\alpha$, the turning down of the leading edge flap was $\gamma=G \alpha$ and the turning up the trailing edge flap was $\beta=-G \alpha$ The same flap motions were seen when the wind direction was reversed.

\subsection{Numerical analysis}

The governing equations of motion with respect to the static equilibrium position of a two-dimensional bridge deck excited by aerodynamic forces are given by

$$
\begin{aligned}
& \ddot{h}+2 \xi_{h} \omega_{h} \dot{h}+\omega_{h}^{2} h=-\frac{L}{m} \\
& \ddot{\alpha}+2 \xi_{\alpha} \omega_{\alpha} \dot{\alpha}+\omega_{\alpha}^{2} \alpha=\frac{M}{I}
\end{aligned}
$$

In which $\mathrm{m}$ is the mass per unit length; $I$ is the moment of inertial per unit length; $\xi_{h}, \xi_{\alpha}$ are the damping ratios of heaving motion $h$ and pitching motion $\alpha$, respectively; $\omega_{h}, \omega_{\alpha}$ are the natural circular frequencies of heaving and pitching motion, respectively; $L$ is the total aerodynamic lift force (positive when upward); $M$ is the total aerodynamic moment (positive when clockwise). $L$ and $M$ are defined in Eqs. (2).

By using the classical thin airfoil theory (Anderson 1984), the static aerodynamic lift $L$ and the aerodynamic moment $M$ are computed by:

$$
\begin{aligned}
& L=1 / 2 \rho U^{2} B\left[C_{L \alpha}^{\prime}\left(\alpha+\frac{\dot{h}}{U}+\frac{W}{U}\right)+C_{L \beta}^{\prime} \beta+C_{L \gamma}^{\prime} \gamma\right] \\
& M=1 / 2 \rho U^{2} B^{2}\left[C_{M \alpha}^{\prime}\left(\alpha+\frac{\dot{h}}{U}+\frac{W}{U}\right)+C_{M \beta}^{\prime} \beta+C_{M \gamma}^{\prime} \gamma\right]
\end{aligned}
$$

In which $\rho$ is the air density, $B=2 b$ is the bridge deck width (see Figure 1), $U$ is the wind speed, $W$ is the vertical wind, $\alpha$ is the angle of attack of the bridge deck, $\beta$ is the angle of the trailing edge flap and $\gamma$ is the angle of the leading edge flap.

The vertical wind is defined as follows:

$$
W=W(t)=\bar{W}+w(t)
$$

where $\bar{W}$ is the mean vertical wind speed, which is assumed to be zero; $w(t)$ is the vertical wind speed. The $\mathrm{W}$ was taken from a gust simulation of the wind tunnel. The coefficients $C$ are the slopes of the aerodynamic force coefficients. They are explained as follows:

$$
\begin{array}{ll}
C_{L \alpha}^{\prime}=2 \pi & C_{M \alpha}^{\prime}=0.5 \pi \\
C_{L \beta}^{\prime}=2\left(\theta_{0}+\sin \theta_{0}\right) & C_{M \beta}^{\prime}=-0.5\left(-\theta_{0}+0.5 \sin 2 \theta_{0}\right) \\
C_{L \gamma}^{\prime}=2\left(-\theta_{0}+\sin \theta_{0}\right) & C_{M \gamma}^{\prime}=-0.5\left(\theta_{0}-0.5 \sin 2 \theta_{0}\right)
\end{array}
$$

where $\theta_{0}=\cos ^{-1} c$ and $c$ indicates the location of a hinge of the flap as shown in Figure 1.

The flaps are passively driven by the pitching motion:

$$
\gamma=X \alpha
$$$$
\beta=Y \alpha
$$

With the known values of all parameters, Eqs. (1) were solved by using the Runge-Kutta method to obtain the

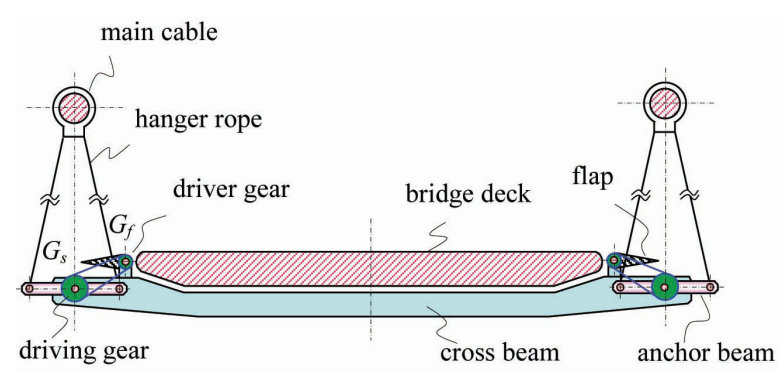

(a) Bridge with flaps (a) Bridge with flaps

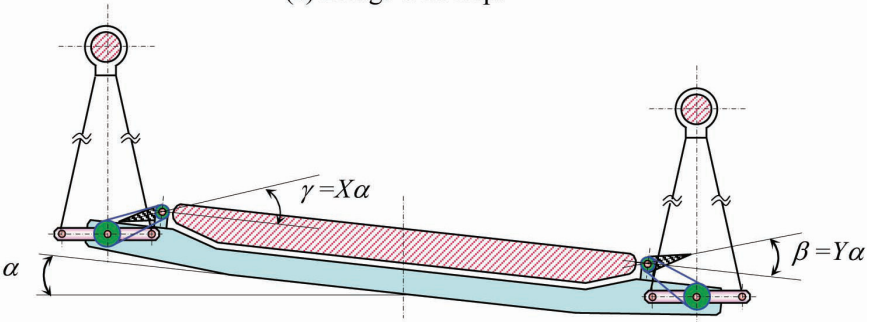

(b) Deformation of bridge and flaps

Fig. 2. Bridge deck with the mechanically driven flaps. 
critical speed and the buffeting responses.

\subsection{Numerical results based on the experimental data}

The model dimensions and the dynamic properties of the investigated system are shown in Table 1 . In still air, the damping ratios and the natural frequencies were measured when the flaps were fixed.

The vertical wind speed $W$ was actively simulated in the Eiffel type wind tunnel based on the Karman's spectrum with the turbulence intensity of $5 \%$ (Kobayashi, et al. 1992, 1994). The results shown in Figure 3 were at the reduced wind speed $U /\left(\omega_{\alpha} b\right)=4.3$, where $\omega_{\alpha}$ is the circular frequency of pitching motion (see Table 1 ).

The sensitivity numerical study in regard to the critical speed was performed with the combination of the coefficients $X=G$ and $Y=-G$ where $G$ varied from -5.5 to 5.5. The instability phenomenon of the bridge deck, which could be flutter, divergence, or large buffeting response, was defined when the pitching response exceeded 0.17 radians in root mean square (RMS). The wind speed at this phenomenon is called the critical speed $U_{c r}$. The equations of motion in the turbulent flow were solved by the Runge-

Table 1. Model dimensions and dynamic properties of the investigated system

\begin{tabular}{|c|c|c|}
\hline \multicolumn{2}{|c|}{ Length $\times$ Width $\times$ Depth $(\mathrm{mm})$} & $408 \times 207 \times 9$ \\
\hline \multicolumn{2}{|c|}{ Width of flap $(\mathrm{mm})$} & 30 \\
\hline \multicolumn{2}{|c|}{ Weight $(\mathrm{kg} / \mathrm{m})$} & 4.28 \\
\hline \multicolumn{2}{|c|}{ Moment of Inertia $\left(\mathrm{kgm}^{2} / \mathrm{m}\right)$} & 0.015 \\
\hline \multirow{2}{*}{$\begin{array}{c}\text { Frequency } \\
(\mathrm{Hz})\end{array}$} & Heaving & 0.998 \\
\cline { 2 - 3 } & Pitching & 1.25 \\
\hline \multirow{2}{*}{ Damping ratio } & Heaving & 0.0047 \\
\cline { 2 - 3 } & Pitching & 0.025 \\
\hline
\end{tabular}

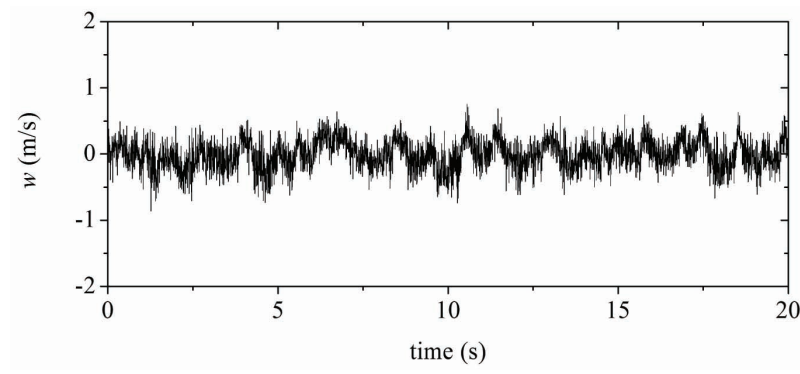

Fig. 3. Time serials of the vertical wind velocity $w$ at $U /\left(\omega_{\alpha} b\right)=4.3$

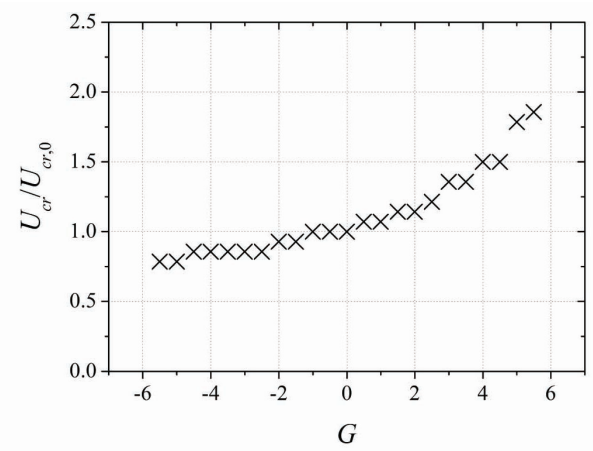

Fig. 4. Effect of $G$ on the flutter control

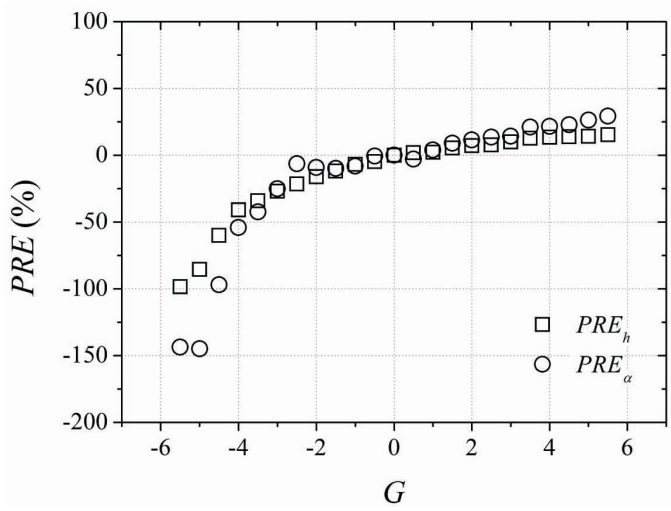

Fig. 5. Effect of $G$ on buffeting control at $U /\left(\omega_{\alpha} b\right)=3.08$

Table 2. The slopes of lift and moment coefficients

\begin{tabular}{|c|c|c|c|}
\hline Coefficient & Theoretical & Measured & Difference (\%) \\
\hline$C_{L \alpha}^{\prime}$ & $2 \pi$ & 4.1 & -34.75 \\
\hline$C_{M \alpha}^{\prime}$ & $\pi / 2$ & 0.63 & -59.90 \\
\hline$C_{L \beta}^{\prime}$ & 2.97 & 0.13 & -95.62 \\
\hline$C_{M \beta}^{\prime}$ & 0.14 & 0.06 & -57.14 \\
\hline$C_{L \gamma}^{\prime}$ & -0.15 & -0.31 & 106.67 \\
\hline$C_{M \gamma}^{\prime}$ & -0.14 & -0.11 & -21.43 \\
\hline
\end{tabular}


Kutta method. The slopes of the aerodynamic force coefficients for the numerical simulation were obtained from experiments done in smooth flow. These values are listed in Table 2.

Figure 4, in which the vertical axis shows the critical speed $U_{c r}$ compared with that of no control case $U_{c r, 0}$, shows the variation of the critical wind speed due to the gain of the control surfaces, $G$. Increase in positive gain resulted in the improvement of the critical wind speed. The maximum ratio $U_{c r} / U_{c r .0}$ was approximately 1.86 when $G$ varied from -5.5 to 5.5. In the case of a further negative decrease of the gain $G$, the critical wind speed became smaller than that of the bridge deck without the control.

To check the effect of the amplifying factor $G$ on buffeting, the percentage of reduction effect for the buffeting response $(P R E)$ is introduced:

$$
P R E_{x}=\left(1-\frac{R M S_{c c}}{R M S_{c 0}}\right)_{x} \times 100 \%
$$

where $R M S_{c c}$ and $R M S_{c 0}$ are the root mean squares of the root mean squares buffeting response for control cases and non-control cases, respectively; the subscript $x$ indicates the heaving $h$ or pitching $\alpha$. Figure 5 shows the effect of the amplifying factor $G$ on the buffeting at $U /\left(\omega_{\alpha} b\right)=3.08$. When $G$ increased, $P R E_{x}$ increased. $P R E_{x}$ reduced and received a negative value when $G<0$.

\section{Wind tunnel test}

\subsection{Wind tunnel model}

The two-dimensional wind tunnel tests were conducted to investigate the effects of the mechanical flaps on the controlling of the wind-induced oscillations. The springmounting of the model and flaps are shown in Figure 6 . Details of the cross sectional shapes are also included.

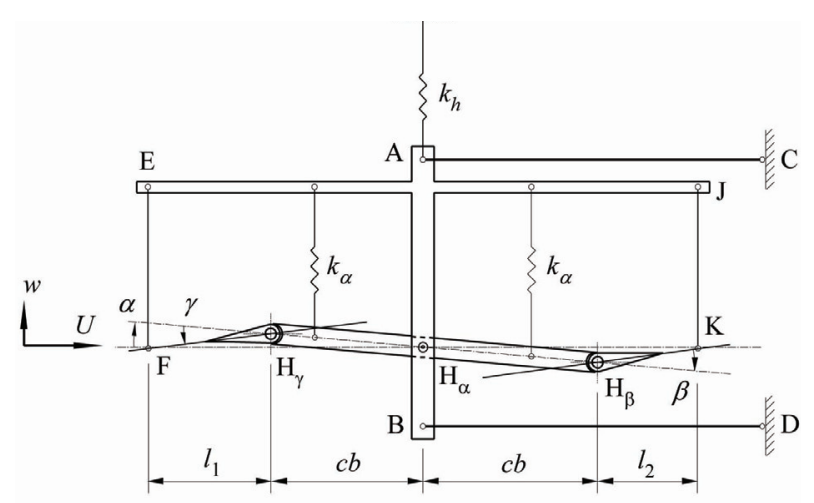

Fig. 6. The wind tunnel model
The model was fixed with the hinge at the point $\mathrm{H}_{\alpha}$ of the supporting frame. The frame was supported by the vertical spring $k_{h}$ which allowed only vertical motion of the frame including the model. The model was elastically supported by the pitching springs $k_{\alpha}$ from the frame allowing only a pitching oscillation about the hinge $\mathrm{H}_{\alpha}$. The sway motion and rotation of the frame was inhibited by the connecting rods $\mathrm{AC}$ and BD. Thus, the model has two degrees of freedom for oscillation, heaving and pitching.

The flaps were installed at both sides of the model. The leading-edge flap had a driving arm $\mathrm{FH}_{\gamma}$ to its end of the rotation axis. During a heaving motion of the modelmounted system, this driving arm did not move. The vertical tie bar EF connected a given point of the driving arm and the frame. The pitching motion of the flap was given by the pitching motion of the bridge deck through the driving arm. The trailing-edge flap also had the same mechanism. Thus, the control manner described in the above section (Figure 2) was realized in this model.

The magnitudes of the flaps depend on the location of the tie bars $E F$ and $J K$ as follows:

$$
\begin{aligned}
& \beta=Y \alpha ; Y=-\left(c b+l_{2}\right) / l_{2} \\
& \gamma=X \alpha ; X=\left(c b+l_{1}\right) / l_{1} \\
& \text { If } l_{1}=l_{2} \text { and } G=\left(c b+l_{1}\right) / l_{1}, \text { the controlling angles are } \\
& \beta=-G \alpha, \gamma=G \alpha .
\end{aligned}
$$

\subsection{Wind-induced responses}

The static aerodynamic force coefficient by the flap was measured in a smooth wind when the angle of attack regarding the bridge deck was 0 degrees. The slopes of the coefficients (derivatives) of the lift and moment among these angles were estimated and compared with the theoretical values on the flat plate. The results are shown in Table 2. A very small lift slope was obtained from the trailing edge flap. It is assumed to be caused by the following reasons. The trailing flap was in a region of the separated flow different from the theoretical flow. In addition, the small gap between the deck and the flap also reduced the aerodynamic force by the flap resulting in the differences between the theoretical and measured values as provided in Table 2. The damping ratios and the frequencies of the model with the controlling flaps were measured in still air. The results are listed in Table 3 . These values changed when factor G changed.

The control effect of the flap control with several values of $G$ was investigated in a turbulent flow. The results are shown in Figure 7. In this figure, the numerical results are also included. The numerical simulation was made with 
parameters listed in Table 3. In this figure, $\omega_{\alpha}$ is the natural frequency of $\omega_{\alpha}$ pitching motion in the case of without control (see Table 1); $b$ is the half-width of the bridge deck. In the experiment case, the flutter motion of the model without control took place at $U_{c r} /\left(\omega_{\alpha} b\right)=3.69$. This speed could be improved to $U_{c r} /\left(\omega_{\alpha} b\right)=6.46$ by the flap control with $G=5.0$. The flap motion by $G=-1.4$ was considered to give a reversed effect for the aerodynamic response. The experimental result by $G=-1.4$ demonstrated that flutter appeared at a slightly lower speed compared with the case without control. The trends for the numerical and simulation results are similar.

An example for the time history of the response in regard to the model with and without flap control in a turbulent flow is shown in Figures 8-10. The time experiment responses

Table 3. Damping and frequency in smooth flow test

\begin{tabular}{|c|c|c|c|c|}
\hline$G$ & $f_{h}(\mathrm{~Hz})$ & $f_{\alpha}(\mathrm{Hz})$ & $\xi_{h}$ & $\xi_{\alpha}$ \\
\hline-1.4 & 1.00 & 1.33 & 0.0050 & 0.036 \\
\hline 0 & 0.99 & 1.25 & 0.0047 & 0.025 \\
\hline 2.3 & 1.01 & 1.26 & 0.0053 & 0.026 \\
\hline 3 & 0.99 & 1.27 & 0.0052 & 0.025 \\
\hline 4.0 & 0.98 & 1.30 & 0.0054 & 0.027 \\
\hline 5.0 & 1.02 & 1.32 & 0.0048 & 0.029 \\
\hline
\end{tabular}

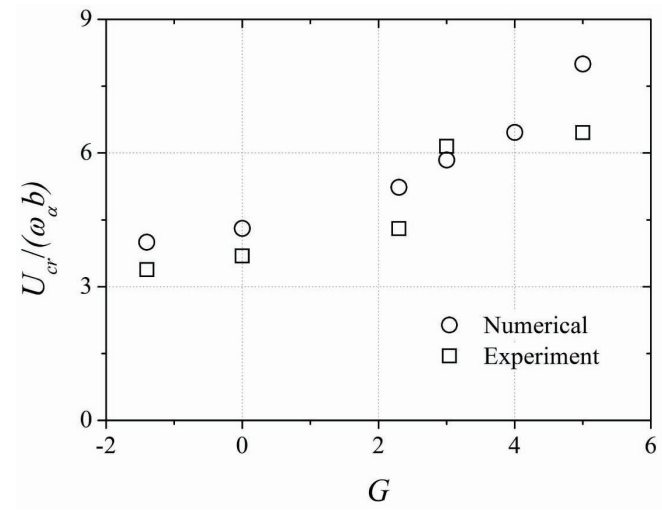

Fig. 7. Reduced wind speed at $G$ on flutter control
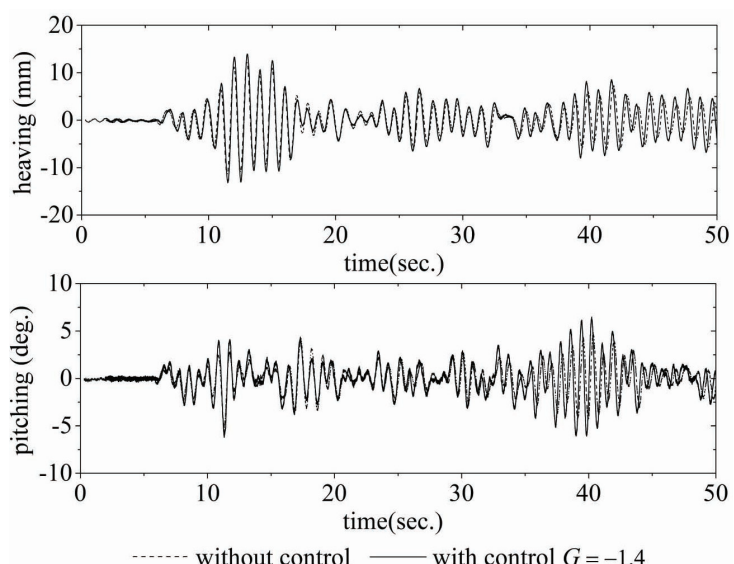

Fig. 8. Time trace, without control $G=0$ and with control $G=-1.4$ at $U /\left(\omega_{\alpha} b\right)=2.77$
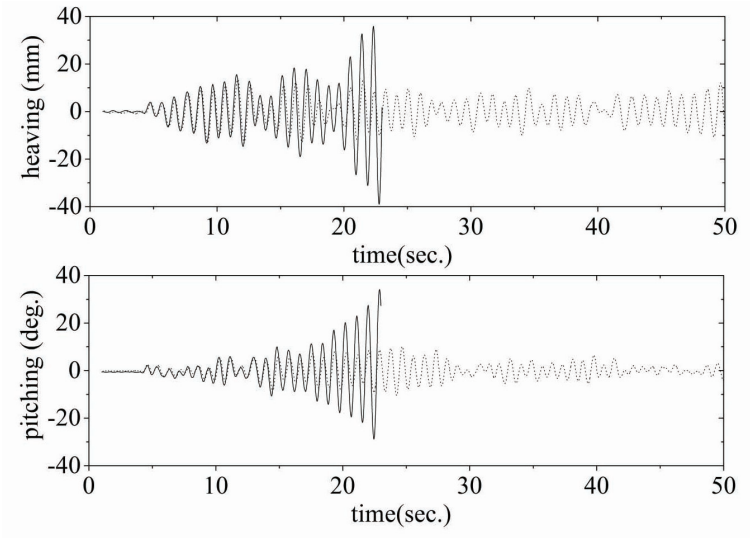

- W.-. without control - with $\operatorname{con}$ trol $G=-1.4$

Fig. 9. Time trace, without control $G=0$ and with control $G=-1.4$ at $U /\left(\omega_{\alpha} b\right)=3.38$
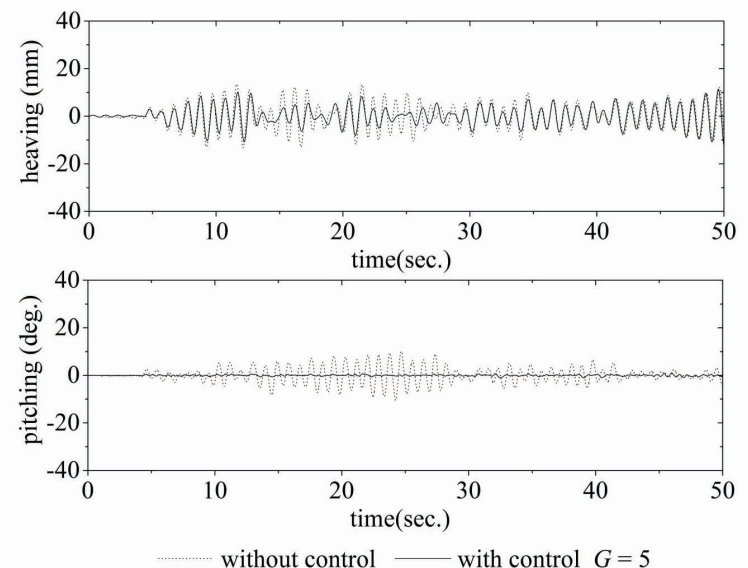

Fig. 10. Time trace, without control $G=0$ and with control $G=5$ at $U /\left(\omega_{\alpha} b\right)=3.38$ 
of heaving and pitching for the reverse effect are shown in Figure 8. For the case without control, $G=0$; and for the case with control $G=-1.4$. The reduced wind speed was $U_{c r} /\left(\omega_{\alpha} b\right)$ $=2.77$. The amplitudes increased after controlling. The reversed effect happened. $\omega_{\alpha}$ was the value at $G=-1.4$. At the flutter speed for the case of $G=-1.4$, as shown in Figure 9, the responses increased exponentially. If the value of $G=5$, the response amplitudes decreased after controlling as shown in Figure 10. The pitching motion completely reduced, but the heaving motion was not affected. If the model was controlled, the flaps were driven with the amplification factor of $G=5.0$, the pitching response was suppressed, however almost no effect on the heaving response was observed.

\section{The three-dimensional mode-by-mode analysis}

\subsection{The aeroelastic full model of suspension bridge}

To apply the flap control to a full span bridge, the following problems were to be investigated. First, the relation between the install flap length and the critical wind speed was examined. Second, the influence of the vibration mode number on the control result was checked. Finally, the buffeting response of the suspension bridge was also tested.

In this numerical study, a simple span suspension bridge with span length $l=3000 \mathrm{~m}$ was employed, which is shown in Figure 11. Details of the bridge model and the flaps for

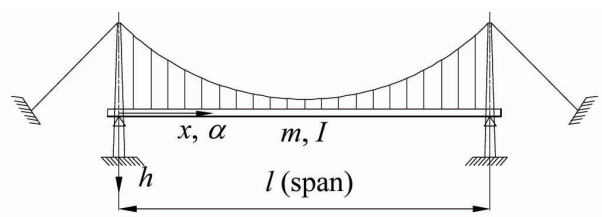

Fig. 11. The suspension bridge model this simulation are listed in Table 4. The damping ratios of bending and torsion modes were assumed to be 0.01 for the mode-by-mode study. This assumption was made for all modes.

The vibration mode shapes and the natural frequencies of bending and torsion motion were obtained by using the finite element method (Abdel-Ghaffar, 1976). The results are shown in Table 5 for the first twenty modes. The lateral motion was neglected in this study.

\subsection{Simulation of turbulent wind field}

The simulation of the vertical turbulent wind field acting on the bridge was carried out. The spectra representation method was used (Paola 1998, Deodatis 1996, Cao et al. 2000, Ding et al. 2006) with the Von-Karman's spectrum formula. The Davenport's coherence function (Davenport 1968) between point $j$ and $m$ was obtained by the following formula:

$$
\operatorname{Coh}\left(\Delta_{j m}, \omega\right)=\exp \left(-\frac{\lambda \omega \Delta_{j m}}{2 \pi U}\right)
$$

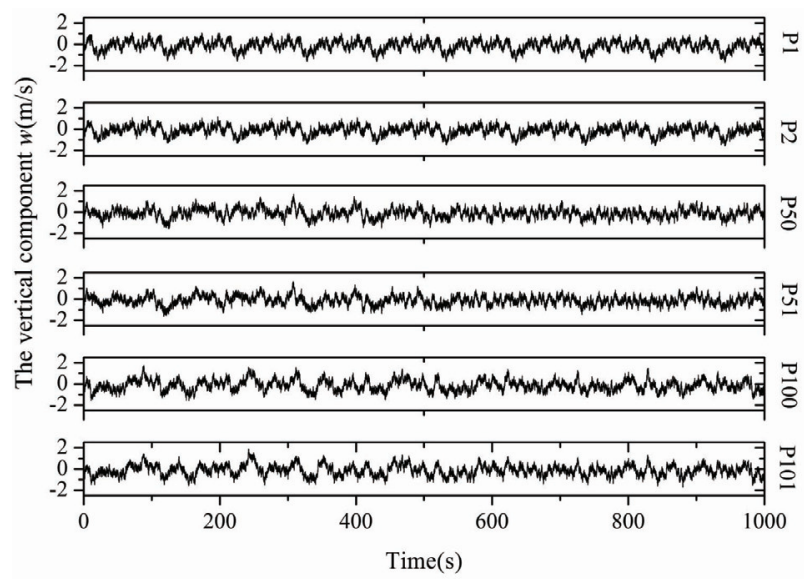

Fig. 12. Sample of vertical turbulent wind at $U=10 \mathrm{~m} / \mathrm{s}$

Table 4. Structural properties of the full bridge model and the flaps

\begin{tabular}{|c|c|c|c|c|}
\hline \multicolumn{2}{|c|}{ Parameters } & Notation & Value & Unit \\
\hline \multirow{4}{*}{$\begin{array}{c}\text { Suspension } \\
\text { bridge }\end{array}$} & Span length & $l$ & 3000 & $\mathrm{~m}$ \\
\cline { 2 - 5 } & Mass & $m$ & $21 \times 10^{3}$ & $\mathrm{~kg} / \mathrm{m}$ \\
\cline { 2 - 5 } & Inertia moment & $I$ & $22 \times 10^{5}$ & $\mathrm{kgm}^{2} / \mathrm{m}$ \\
\cline { 2 - 5 } & Deck width & $B$ & 35.5 & $\mathrm{~m}$ \\
\cline { 2 - 5 } & Damping (bending) & $\xi_{b}$ & 0.01 & - \\
\cline { 2 - 5 } & Damping (torsion) & $\xi_{t}$ & 0.01 & - \\
\hline Flap & Length of a unit flap & $\Delta l_{F}$ & 30 & $\mathrm{~m}$ \\
\hline
\end{tabular}


In which $\omega$ is the frequency; $\lambda$ is the dimensionless decay factor; $\Delta_{j m}=\Delta|j-m|$ is the horizontal distance from point $\mathrm{j}$ to $m$. $\triangle$ is the distance interval between successive points. These parameters are listed in Table 6. Figure 12 presents the first $1000 \mathrm{sec}$ samples of the vertical turbulent wind field at point $P 1$ (left support), P2, P50 (midpoint), P51, P100 and $P 101$ (right support). The mean wind speed in this case was $10 \mathrm{~m} / \mathrm{s}$.

\subsection{Numerical analysis}

The bridge deck motions were assumed by the combination of one bending mode and one torsion mode as follows:

$$
\begin{aligned}
& h=h(x, t)=\phi_{b}(x) B g_{b}(t) \\
& \alpha=\alpha(x, t)=\phi_{t}(x) g_{t}(t)
\end{aligned}
$$

where $\phi_{b}(x), \phi_{t}(x)$ are the mode shapes of bending and torsion, respectively; $g_{b}(t), g_{t}(t)$ are the generalized coordinates of bending and torsion, respectively; $x$ is the span-wise coordinate. In this study, the first three modes of bending and torsion were examined. The lateral mode was not considered. The response calculation was conducted based on the modal analysis with the second order equations of motion composed of one of the bending modes and one of the torsion modes.

Referring to Eqs. (1), the equations of motion in modal analysis become

$$
\begin{aligned}
& \ddot{g}_{b}+2 \xi_{b} \omega_{b} \dot{g}_{b}+\omega_{b}^{2} g_{b}=-\int_{\text {span }} L(x, t) \varphi_{b}(x) B d x / I_{0 b} \\
& \ddot{g}_{t}+2 \xi_{t} \omega_{t} \dot{g}_{t}+\omega_{t}^{2} g_{t}=\int_{\text {span }} M(x, t) \varphi_{t}(x) d x / I_{0 t}
\end{aligned}
$$

where $I_{0 b}$ and $I_{0 t}$ are the bending and torsion generalized inertias, respectively

$$
I_{0 b}=B^{2} \int_{\text {span }} m(x) \varphi_{b}^{2}(x) d x \quad I_{0 t}=\int_{\text {span }} I(x) \varphi_{t}^{2}(x) d x
$$

The buffeting forces and the self-excited forces are the

\begin{tabular}{|c|c|c|c|c|c|c|c|}
\hline Mode & Natural frequency $f$ & Moc & type & Mode & Natural frequency & \multicolumn{2}{|c|}{ Mode type } \\
\hline 1 & 0.056 & 1_V & VS & 11 & 0.282 & 4_T & TAS \\
\hline 2 & 0.076 & $2 \_\mathrm{V}$ & VAS & 12 & 0.307 & 8_V & VAS \\
\hline 3 & 0.101 & 1_T & TS & 13 & 0.347 & 9_V & VS \\
\hline 4 & 0.115 & $3 \_\mathrm{V}$ & VS & 14 & 0.353 & 5_T & TS \\
\hline 5 & 0.141 & 2_T & TAS & 15 & 0.388 & 10_V & VAS \\
\hline 6 & 0.152 & 4_V & VAS & 16 & 0.424 & 6_T & TAS \\
\hline 7 & 0.190 & $5 \_\mathrm{V}$ & VS & 17 & 0.429 & 11_V & VS \\
\hline 8 & 0.213 & 3_T & TS & 18 & 0.470 & $12 \_\mathrm{V}$ & VAS \\
\hline 9 & 0.229 & $6 \_\mathrm{V}$ & VAS & 19 & 0.495 & 7_T & TS \\
\hline 10 & 0.268 & 7_V & VS & 20 & 0.513 & 13_V & VS \\
\hline
\end{tabular}
sum of the forces on the bridge deck and the flaps. $U(x, t)$ is assumed to be constant with time and space. The vertical turbulent wind $w(x, t)$ has a span-wise correlation. The flap

Table 5. The first twenty natural frequencies of the bridge

Table 6. Characteristic values of the wind field simulation

\begin{tabular}{|l|c|c|c|}
\hline \multicolumn{1}{|c|}{ Parameters } & Notation & Value & Unit \\
\hline Gust simulation point numbers & $N$ & 101 & - \\
\hline Distance between successive points & $\Delta$ & 30 & $m$ \\
\hline Decay factor & $\lambda$ & 8 & - \\
\hline Turbulent integral length scale & $L_{w}$ & 150 & $m$ \\
\hline Turbulence intensity & $I_{w}$ & $5 \%$ & - \\
\hline
\end{tabular}


with length $\triangle l_{F}$ is installed at $\mathrm{x}_{j}, j=1,2 \ldots N$, where $N$ is the divided number of the span.

By replacing $\alpha$ in Eqs. (5) by Eqs. (9), with $X=G$ and $Y=-G$, the flap angles at position $x$ and at time $t$ are driven by the following equations:

$$
\begin{aligned}
& \gamma(x, t)=G \varphi_{t}(x) g_{t}(t) \\
& \beta(x, t)=-G \varphi_{t}(x) g_{t}(t)
\end{aligned}
$$

In Eqs. (12), the coefficients $G=5$ is used for the control case. The three methods of the flap arrangement as shown in Figure 13 are employed here. In method 1, the flap is installed partially at the center of the span. The installed portion corresponds to the hoop of the first natural vibration mode shape. The locations of the flap of method 2 and 3 correspond to the hoops of the natural vibration modes for the second and the third, respectively.

Bridge deck motions are assumed by the combination of one bending mode and one torsion mode, bending and torsion of bridge deck are defined by the Eqs. (9) and (10). If the flap angles are derived by Eqs. (12), the equations of motion for the full span of the bridge are:

$$
\begin{aligned}
& \ddot{g}_{b}+2 \xi_{b} \omega_{b} \dot{g}_{b}+\omega_{b}^{2} g_{b}=\frac{\pi Q_{s e 0}}{I_{0 b} B}\left[H_{1} \frac{\dot{g}_{b} B}{U}+H_{2} g_{t}+H_{b}\right] \\
& \ddot{g}_{t}+2 \xi_{t} \omega_{t} \dot{g}_{t}+\omega_{t}^{2} g_{t}=\frac{\pi Q_{s e 0}}{4 I_{0 t}}\left[K_{1} \frac{\dot{g}_{b} B}{U}+K_{2} g_{t}+K_{b}\right]
\end{aligned}
$$

where

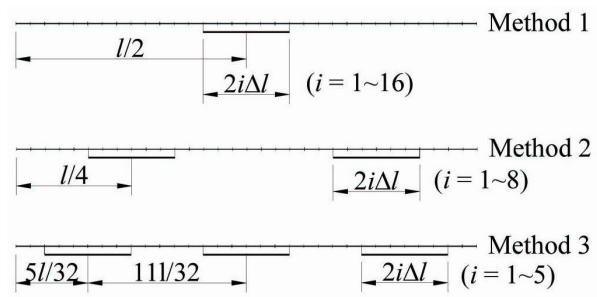

Fig. 13. Flap arrangement.

$$
Q_{s e 0}=\rho U^{2} B^{2}
$$

$$
H_{1}=-\frac{C_{L \alpha}^{\prime}}{2 \pi} B G_{b b}
$$$$
H_{2}=-\frac{C_{L \alpha}^{\prime}}{2 \pi} B G_{b t}-\frac{C_{L \gamma}^{\prime}-C_{L \beta}^{\prime}}{2 \pi} G B G_{b t}^{F}
$$$$
H_{b}=-\frac{C_{L \alpha}^{\prime}}{2 \pi} B \int_{\text {span }} \varphi_{b}(x) \frac{w(x)}{U} d x
$$

$$
G_{m n}=\int_{s p a n} \varphi_{m}(x) \varphi_{n}(x) d x, m, n=b, t
$$

$$
G_{m n}^{F}=\int_{s p a n} \varphi_{m}(x) \varphi_{n}(x) \psi_{F}(x) d x, m, n=b, t
$$$$
K_{1}=\frac{2 C_{M \alpha}^{\prime}}{\pi} B G_{b t}
$$$$
K_{2}=\frac{2 C_{M \alpha}^{\prime}}{\pi} G_{t t}+\frac{2\left(C_{M \gamma}^{\prime}-C_{M \beta}^{\prime}\right)}{\pi} G G_{t t}^{F}
$$$$
K_{b}=\frac{2 C_{M \alpha}^{\prime}}{\pi} \int_{\text {span }} \varphi_{t}(x) \frac{w(x)}{U} d x
$$

where $\psi_{F}$ is a forcing function taking the value of 1 where flap is installed and is 0 otherwise.

\subsection{Numerical results}

At first, the critical speed of the bridge deck without controlling was checked. The result is shown in Table 7. In which, modes $(i-j)$ means the combination of the $\mathrm{i}^{\text {th }}$ bending mode and the $j^{\text {th }}$ torsion mode. The term $\omega_{\alpha 1}$ is the torsion natural frequency of the first mode. For the mode combinations (1-1), (2-2) and (3-3), the critical phenomenon was flutter. In addition, the divergence motion took place in the mode combinations (1-2), (2-1), (2-3) and (3-2). In the design of a bridge, only the lowest critical speed, in this case the mode combinations (1-1), is important. However, in this study, all the mode combinations shown in Table 7 were investigated.

Table 7. Critical speeds - without flap

\begin{tabular}{|c|c|c|}
\hline Modes & $U_{c r} /\left(\omega_{\alpha 1} b\right)$ & Note \\
\hline$(1-1)$ & 1.26 & Flutter for the first mode \\
\hline$(2-2)$ & 1.79 & Flutter for the second mode \\
\hline$(3-3)$ & 2.69 & Flutter for the third mode \\
\hline$(2-1)$ & 3.23 & Divergence for the first torsion mode \\
\hline$(1-2),(3-2)$ & 4.66 & Divergence for the second torsion mode \\
\hline$(2-3)$ & 7.17 & Divergence for the third torsion mode \\
\hline
\end{tabular}


The critical speeds were checked for the arrangement methods with a variation of the flap length ratio, and modes $(i-j)$. The flap length ratio FLR is defined by the ratio of the flap length on one side and the span length. The results are depicted in Figure 14. In case of modes(1-1) without control, the flutter speed was 1.26. After controlling, the flaps installed for about $50 \%$ of the span length could increase the flutter speeds of the modes(1-1) up to 2.28, approximately 1.8 times compared to without control. From the results of this analysis and the plots in Figure 14, it was determined that the flaps could improve the critical speed of the bridge. They controlled the flutter speed well.

The arrangement method 1 could increase the flutter speeds of the modes(2-2) up to 4.19, approximately 2.34 times compared to without control. It was also effective for divergence. Modes(1-2), (2-1), (2-3), (3-2) were the divergence cases. Modes(1-2) and (3-2) were of the same effect, because of the same pitching mode 2 . In the real case, the arrangement method 2 is more realistic since the length of the hung cable was long enough to produce the relation motion between the flap and bridge, as discussed above. This method also increased the flutter speed and the divergence speed. The same effect could be seen in the arrangement method 3.

\section{Conclusion and Discussion}

A mechanically turning flap to control the aerodynamic stability was studied with the quasi-steady force approach. We have demonstrated that the quasi-steady force is easy to be applied in the time domain. In the two-dimensional study, the experimental force coefficients and vertical wind gust were used to both simulate and find the best control. The amplification factor $G$ was investigated in the viewpoint of the large flutter speed and the small buffeting response. The following remarks were addressed:

- The quasi-steady force was reasonably accepted to investigate the efficiency of the amplification factor $G$. The control manner for the leading-edge flap and the training-edge flap such as $\gamma=G \alpha$ and $\beta=-G \alpha$ can be easily set up in a real case. The positive values of $G$ can be applied to suppress the buffeting response and improve the flutter speed or to improve the aerodynamic stability of the bridge deck. The negative values of $G$ had the reverse effect. The numerical results using the experimental frequencies and damping ratios were compared to the experiment cases to check the efficiency of the flap control and to validate the quasi-steady force method.

- In a turbulent flow, control by $G=5.0$ also improved the flutter speed approximately 2 times and suppressed the divergence phenomenon up to its wind speed. Buffeting in the pitching motion was effectively suppressed but the heaving motion was not.

The quasi-steady force method was also applied for full span bridge to check the efficiency of the flap control. Effects of the flap location, the flap length, and the mode shapes on the control were investigated. The mode-by-mode technique of coupled motions was considered. The flutter speed and the buffeting response for with and without the control were computed. The parameters used in the numerical analysis were the same with those in the two-dimensional cases. The following results were found by the mode-by-mode technique:

- The flaps installed for about $50 \%$ of the span length could increase the flutter speed of the modes(1-1) up to approximately 1.8 times.

- For divergence, the passive flap control was proven to be effective.

\section{References}

[1] Anderson, J.D, Fundamentals of Aerodynamics, McGraw-Hill, New York, 1984.

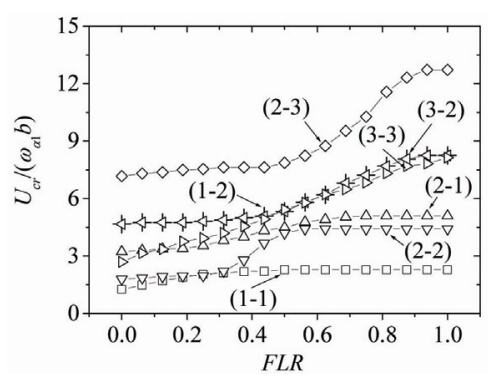

(a) Arrangement method 1

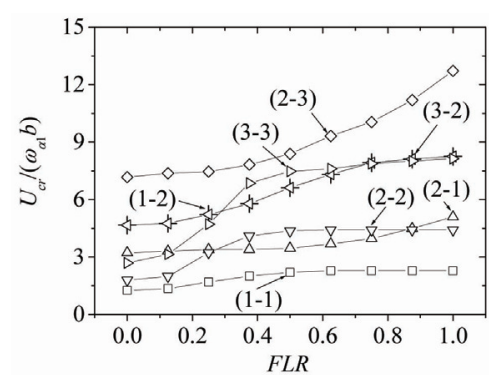

(b) Arrangement method 2

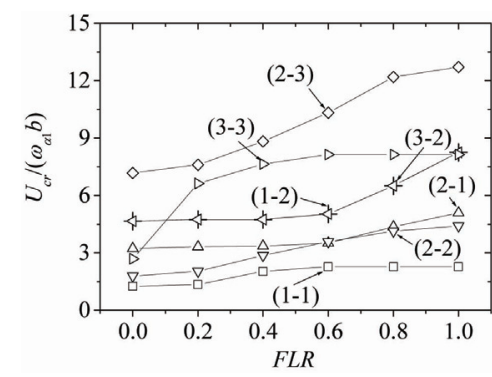

(c) Arrangement method 3

Fig. 14. Flutter speed improvement by FLR with different modes 
[2] Brancaleoni, F., "The construction phase and its aerodynamic issues, Aerodynamics of Large Bridges (ed. Larsen)", Balkema, 1992, pp. 147-158.

[3] Brown, W. C., "Development of the deck for the 3300m span Messina”, 15th IABSE Congr. Rep., IABSE, Zurich, 1996, pp. 1019-1030.

[4] Brown, W.C., "Long span bridge project - a personal view", Proc. of the international seminar on Long-Span Bridges and Aerodynamics, Springer, 1999, pp. 3-19.

[5] Cao, B., and Sarkar, P. P., "Identification of Rational Functions using two-degree-of-freedom model by forced vibration method", Engineering. Structures, Vol. 43, 2012, pp. 21-30.

[6] Chen, X., Matsumoto, M., and Kareem, A., "Aerodynamic coupling effects on flutter and buffeting of bridges", J. of Eng. Mech., Vol. 126, No. 1, 2000, pp. 7-26.

[7] Chen, X., and Kareem, A., "Nonlinear response analysis of long-span bridges under turbulent winds", J. Wind Eng. Ind. Aerodyn., Vol. 89, No. 14, 2001, pp. 1335-1350.

[8] Costa, C., and Borri, C., "Application of indicial functions in bridge deck aeroelasticity", J. Wind Eng. Ind. Aerodyn., Vol. 94, No. 11, 2006, pp. 859-881.

[9] Dung, N., Miyata, T., and Yamada, H., "Application of robust control to the flutter of long - span bridges", J. Struct. Eng., Vol. 42A, 1996, pp. 847 - 853.

[10] Fok, C.H., Kwok, K.C.S., Qin, X.R., and Hitchcock, P.A., "Sectional pressure tests of a twin-deck bridge: part 1: experimental techniques and effects of angle of wind incidence", Proc. of 11th AWES Workshop, Darwin, Australia, 2004.

[11] Fok, C.H., Kwok, K.C.S., Qin, X.R., and Hitchcock, P.A., "Sectional pressure tests of a twin-deck bridge: Part 2: effects of gap-width on a twin-deck configuration". Proc. of 11th AWES, Workshop, Darwin, Australia, 2004.

[12] Ge, Y., Zou, X., and Yang, Y., "Aerodynamic stabilization of central stabilizers for box girder suspension bridges", Wind and Structures, Vol. 12, No. 4, 2009, pp. 285-295.

[13] Gua, M., Chang, C.C., Wua, W., and Xiang, H.F., "Increase of critical flutter wind speed of long-span bridges using tuned mass dampers", J. Wind Eng. Ind. Aerodyn., Vol. 73, 1998, pp. 111-123.

[14] Gua, M., Chena, S.R., and Chang, C.C., "Parametric study on multiple tuned mass dampers for buffeting control of Yangpu Bridge", J. Wind Eng. Ind. Aerodyn., Vol. 89, 2001, pp. 987-1000.

[15] Gua, M., Chena, S.R., and Chang, C.C., "Control of wind-induced vibrations of long-span bridges by semiactive lever-type TMD", J. Wind Eng. Ind. Aerodyn., Vol. 90, 2002, pp. 111-126.

[16] Kobayashi, H., and Nagaoka, H., "Active control of flutter of a suspension bridge", J. Wind Eng. Ind. Aerodyn., Vol. 41, No. 1 - 3, 1992, pp. 143-151.

[17] Kobayashi, H., and Hatanaka, A., "Active generation of wind gust in a two-dimensional wind tunnel", J. Wind Eng. Ind. Aerodyn., Vol. 42, No. 1-3, 1992, pp. 959-970.

[18] Kobayashi, H., Hatanaka, A., and Ueda, T., "Active simulation of time histories of strong wind gust in a wind tunnel", J. Wind Eng. Ind. Aerodyn., Vol. 53, 1994, pp. 315-330.

[19] Kobayashi, H., and Nitta, Y., "Active flutter control of suspension bridge by control surfaces", Third International Conference on Motion and Vibration Control, Chiba, 1996, pp. 1-6.

[20] Kobayashi, H., Ogawa, R., and Taniguchi, S., "Active flutter control of a bridge deck by ailerons", Proc, 2nd World Conf. on Structural Control, Kyoto, 1998.

[21] Kobayashi, H., Mitani, K., and Ogawa, "Active buffeting control by flaps", The Fifth Asia-Pacific Conference on Wind Engineering, 2001.

[22] Kobayashi, H., and Phan, D.-H., "Bridge deck flutter control by control surfaces", Proc, 6th Asia-Pacific Conf. on Wind Engineering, Seoul, Korea, 2005.

[23] Körlin, R., and Starossek, U., "Wind tunnel test of an active mass damper for bridge decks", J. Wind Eng. Ind. Aerodyn., Vol. 95, 2007, pp. 267-277.

[24] Kwon, S. D., Jung, S., and Chang, S.P., "A new passive aerodynamic control method for bridge flutter", J. Wind Eng. Ind. Aerodyn., Vol. 86, 2000, pp. 187-202.

[25] Kwon, S. D., and Park, K.-S., "Suppression of bridge flutter using tuned mass dampers based on robust performance design", J. Wind Eng. Ind. Aerodyn., Vol. 92, 2004, pp. 919-934.

[26] Kwok, K.C.S., Qin, X.R., Fok, C.H., and Hitchcock, P.A., "Wind-induced pressures around a sectional twindeck bridge model: Effects of gap-width on the aerodynamic forces and vortex shedding mechanisms", J. Wind Eng. Ind. Aerodyn., Vol. 110, 2012, pp. 50-61.

[27] Lin, Y. Y., Cheng, C.-M., and Lee C.-H., "A tuned mass damper for suppressing the coupled flexural and torsional buffeting response of long-span bridges", Eng. Struct., Vol. 22, 2000, pp. 1195-1204.

[28] Miyata, T., Yamada, H., Dung, N., and Kazama, K., “On active control and structural response control of the coupled flutter problem for long span bridges", 1st World Conf. on Structural Control, Los Angeles, California, USA, 1994.

[29] Nissen, H. D., Sørensen, P. H., and Jannerup, O., "Active aerodynamic stabilisation of long suspension bridges", J. Wind Eng. Ind. Aerodyn., Vol. 92, 2004, pp. 829-847.

[30] Okada, T., Honke, K., Sugii, K., Shimada, S., and Kobayashi, H., "Suppression of coupled flutter of a bridge deck by tuned pendulum damper", Proc, 3rd World Conf. on 
Structural Control, Kyoto, 1998.

[31] Omenzetter, P., Wilde, K., and Fujino, Y., "Suppression of wind-induced instabilities of a long span bridge by a passive deck-flaps control system. Part I: Formulation", J. Wind Eng. Ind. Aerodyn., Vol. 87, No. 1, 2000, pp. 61-79.

[32] Omenzetter, P., Wilde, K., and Fujino, Y., "Suppression of wind-induced instabilities of a long span bridge by a passive deck-flaps control system. Part II: Numerical simulations", J. Wind Eng. Ind. Aerodyn., Vol. 87, No. 1, 2000, pp. 81-91.

[33] Omenzetter, P., Wilde, K., and Fujino, Y., "Study of passive deck-flaps flutter control system on full bridge model. I: theory", J. Engrg. Mech., Vol. 128, No. 3, 2002, pp. 264-279.

[34] Omenzetter, P., Wilde, K., and Fujino, Y., "Study of passive deck-flaps flutter control system on full bridge model. II: results", J. Engrg. Mech., Vol. 128, No. 3, 2002, pp. 280-286.

[35] Ostenfeld, K. H., and Larsen, A., "Bridge engineering and aerodynamics, Aerodynamics of Large Bridges, Larsen A. (ed.)", Balkema, Rotterdam, 1992.

[36] Peidikman, S., and Mook, D.T., "On the development of a passive-damping system for wind-excited oscillation of long-span bridges", J. Wind Eng. Ind. Aerodyn., Vol. 77-78, 1998, pp. 443-456.

[37] Phan, D.-H., and Kobayashi, H., "An experimental study of flutter and buffeting control of suspension bridge by mechanically driven flaps", Wind and Structures, Vol. 14, No. 2, 20011, pp. 152-163.

[38] Sato, H., Kusuhara, S., Ogi, K., and Matsufuji, H., "Aerodynamic characteristics of super long-span bridges with slotted box girder", J. Wind Eng. Ind. Aerodyn., Vol. 88, No. 2-3, 2000, pp. 297-306.
[39] Sato, H., Hirahara, N., Fumoto, K., Hirano, S., and Kusuhara, S., "Full aeroelastic model test of a super longspan bridge with slotted box girder", J. Wind Eng. Ind. Aerodyn., Vol. 90, No. 12-15, 2002, pp. 2023-2032.

[40] Scanlan, R. H., Béliveau, J-G, and Budlong, K. S., "Indicial aerodynamic functions for bridge decks". J. The Eng. Mech. Division, Vol. 100, No. 4, 1974, pp. 657-672.

[41] Scanlan, R. H., and Tomko, J. J., "Indicial aerodynamic functions for bridge decks". J. The Eng. Mech. Division, Vol. 97, No. 6, 1971, pp. 1717-1737.

[42] Shubov, M. A., "Mathematical modeling and analysis of flutter in long-span suspension bridges and in blood vessel walls", J. Aero. Eng., Vol. 17, No. 2, 2004, pp. 70-82.

[43] Songpol, P., "Analytical study on flutter suppression by eccentric mass method on 3D full suspension bridge model", Proc, 3rd World Conf. on Structural Control, Kyoto, 1998.

[44] Ubertini, F., "Prevention of suspension bridge flutter using multiple tuned mass dampers". Wind and Structures, Vol. 13, No. 3, 2010, pp. 235-256.

[45] Wilde, K., Fujino, Y., and Kawakami, T., "Analytical and experimental study on passive aerodynamic control of flutter of a bridge deck", J. Wind Eng. Ind. Aerodyn., Vol. 80, 1999, pp. 105-119.

[46] Wilde, K., and Fujino, Y., "Aerodynamic control of bridge deck flutter by active surfaces", J. Eng. Mech., Vol. 124, No. 7, 1998, pp. 718-727.

[47] Wilde, K., Fujino, Y., and Prabis, V., "Effects of eccentric mass on flutter of long span bridge”, Proc, 2nd Int. Workshop on Structural Control, Hong Kong, 1996.

[48] Zhang, C. W., Li, J. L., Li, H., and Ou, J. P., "Preliminary Numerical Study on TRID System for Flutter Vibration Control of Bridge Structure", Procedia Engineering, Vol. 14, 2011, pp. 2796-2806. 